\title{
EXISTENCE THEOREMS OF A NEW SET-VALUED MT-CONTRACTION IN $b$-METRIC SPACES ENDOWED WITH GRAPHS AND APPLICATIONS
}

\author{
JUKRAPONG TIAMMEE*,1, SUTHEP SUANTAI** AND YEOL JE CHO*** \\ *Department of Mathematics and Statistics, Faculty of Science and Technology \\ Chiang Mai Rajabhat University, Chiang Mai 50300, Thailand \\ E-mail: jukrapong.benz@gmail.com \\ ** Department of Mathematics, Faculty of Science \\ Chiang Mai University, Chiang Mai 50200, Thailand \\ E-mail: suthep.s@cmu.ac.th \\ *** Department of Education and the RINS, Gyeongsang National University \\ Jinju 660-701, Korea \\ Center for General Education, China Medical University \\ Taichung, 40402, Taiwan \\ E-mail: yjcho@gnu.ac.kr
}

\begin{abstract}
A new concept of set-valued Mizoguchi-Takahashi $G$-contractions is introduced in this paper and some fixed point theorems for such mappings in $b$-metric spaces endowed with directed graphs are established under some sufficient conditions. Our results improve and extend those of [20] and [24]. We also give some examples supporting our main results. As an applications, we prove the existence of fixed points for multivalued mappings satisfying generalized MT-contractive condition in $\epsilon$-chainable $b$-metric spaces and the existence of a solution for some integral equations.

Key Words and Phrases: Fixed point, Mizoguchi-Takahashi function, $b$-metric spaces, directed graph, set-valued map, integral equation, $\epsilon$-chainable metric space.

2010 Mathematics Subject Classification: 47H04, 47H10, 54H25.
\end{abstract}

Acknowledgements. The authors would like to thank the Thailand Research Fund under the project RTA5780007 and Chiang Mai University, Chiang Mai, Thailand for the financial support. The first author would like to thanks Chiang Mai Rajabhat University, Chiang Mai, Thailand for the financial support. The third author was supported by Basic Science Research Program through the National Research Foundation of Korea (NRF) funded by the Ministry of Science, ICT and future Planning (2014R1A2A2A01002100).

\footnotetext{
${ }^{1}$ Corresponding author.
} 


\section{REFERENCES}

[1] M.U. Ali, T. Kamran, M. Postolache, Fixed point theorems for multivalued G-contractions in Hausdorff b-gauge spaces, J. Nonlinear Sci. Appl., 8(2015), no. 5, 847-855.

[2] I.A. Bakhtin, The contraction mapping principle in quasi-metric spaces, (Russian), Functional Anal., 30(1989), 26-37.

[3] S. Banach, Sur les operations dans les ensembles abstraits et leur application aux equations integrales, Fundam. Math., 3(1922), 133-181.

[4] I. Beg, A.R. Butt, The contraction principle for set valued mappings on a metric space with graph, Comput. Math. Appl., 60(2010), 1214-1219.

[5] M. Berinde, V. Berinde, On a general class of multi-valued weakly Picard mappings, J. Math Anal. Appl., 326(2007), 772-782.

[6] V. Berinde, M. Pacurar, The role of Pompeiu-Hausdorff metric in fixed point theory, Creat. Math. Inform., 22, 143-150.

[7] V. Berinde, Generalized contractions in quasi metrics paces, Seminar on Fixed Point Theory, 1993, 3-9.

[8] M. Boriceanu, Fixed point theory for multivalued generalized contraction on a set with two b-metrics, Stud. Univ. Babes-Bolyai Math., 54(2009), no. 3, 3-14.

[9] M. Boriceanu, M. Bota, A. Petruşel, Multivalued fractals in b-metric spaces, Cent. Eur. J. Math., 8(2010), 367-377.

[10] S. Czerwick, Nonlinear set-valued contraction mappings in b-metric spaces, Atti del Semin. Mat. e Fisico dell' Univ. di Modena, 46(1998), 263-276.

[11] S. Czerwick, K. Dlutek, S.L. Singh, Round-off stability of iteration procedures for set-valued operators in b-metric spaces, J. Natural Physical Sci., 11(2007), 87-94.

[12] S. Czerwick, Contraction mappings in b-metric spaces, Acta Math. Inform. Univ. Ostraviensis, 1(1993), 5-11.

[13] T. Dinevari, M. Frigon, Fixed point results for multivalued contractions on a metric space with a graph, J. Math. Anal. Appl., 405(2013), 507-517.

[14] W.S. Du, On coincidence point and fixed point theorems for nonlinear multivalued maps, Topology and its Applications, 159(2012), 49-56.

[15] M. Edelstein, An extension of Banach's contraction principle, Proc. Amer. Math. Soc., 12(1961), 7-10.

[16] A. Erduran, M. Abbas, Fixed point theory for suzuki type $(\theta, L)$-weak multivalued operators, Fixed Point Theory, 16(2015), no. 2, 303-312.

[17] J. Jachymski, The contraction principle for mappings on a metric space with a graph, Proc. Amer. Math. Soc., 136(2008), 1359-1373.

[18] M. Javahernia, A. Razani, F. Khojasteh, Common fixed point of generalized MizoguchiTakahashi's type contractions, Fixed Point Theory Appl., 2014, 2014:195.

[19] C. Klanarong, S. Suantai, Coincidence point theorems for some multi-valued mappings in complete metric spaces endowed with a graph, Fixed Point Theory Appl., 2015, 2015:129, 16 pp.

[20] N. Mizoguchi, W. Takahashi, Fixed point theorems for multivalued mappings on complete metric spaces, J. Math. Anal. Appl., 141(1989), 177-188.

[21] S. Nadler, Jr., Multi-valued contraction mappings, Pacific J. Math., 20(1969), 475-488.

[22] H.K. Pathak, R.P. Agarwal, Y.J. Cho, Coincidence and fixed points for multi-valued mappings and its application to nonconvex integral inclusions, J. Comput. Appl. Math., 283(2015), 201217.

[23] S. Reich, Fixed points of contractive functions, Boll. Un. Mat. Ital., 5(1972), 26-42.

[24] A. Sultana, V. Vetrivel, Fixed points of Mizoguchi-Takahashi contraction on a metric space with a graph and applications, J. Math. Anal. Appl., 417(2014), 336-344.

[25] J. Tiammee, S. Suantai, Coincidence point theorems for graph-preserving multi-valued mappings, Fixed Point Theory Appl. 2014, 2014:70, 11 pp.

[26] J. Tiammee, S. Suantai, Coincidence point theorems for multi-valued mappings of Reich-type on metric spaces endowed with a graph, J. Nonlinear Convex Anal., 16(2015), no. 2, 365-373. 
Received: March 24, 2016; Accepted: October 13, 2016. 